\title{
Bioactive coating on 321AISI stainless steel alloy and used for biomedical Implants
}

\author{
Ayman A. Ahmmed \\ Department of Physiology / Collage of Medicine \\ University of Mosul
}

Received

14 / 10 / 2009
Accepted

02 / 11 / 2009

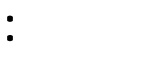

في هذا البهث قمطلاء عينت من الفولاذ المقاوم للصدأم ن ن - 321AISI طبقة

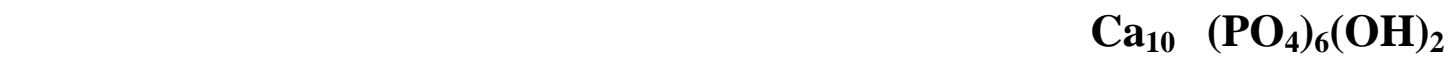

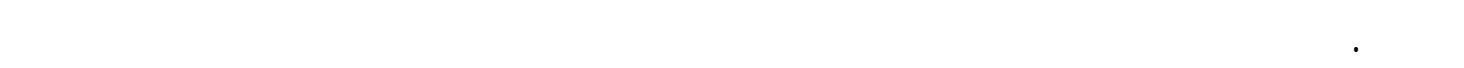

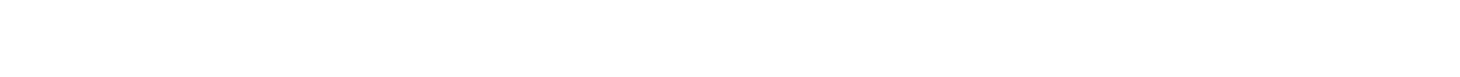

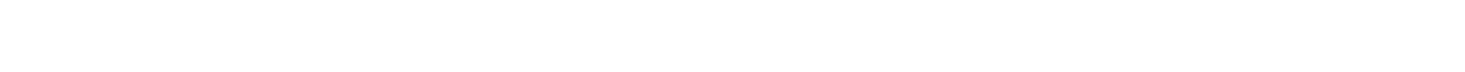
والبدل المزروع وهذا يؤدي إلى عملية تشبيت لهذه البدالٍ.

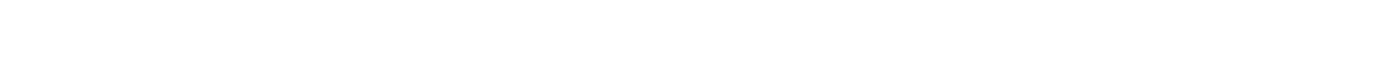

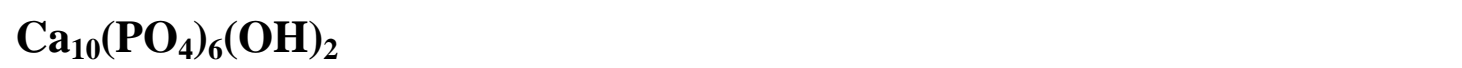

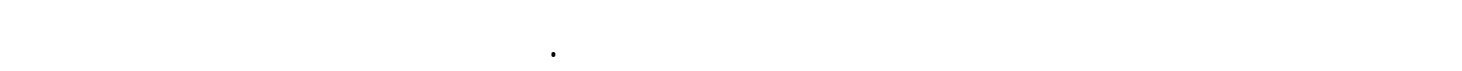

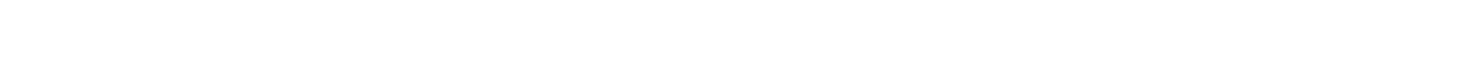

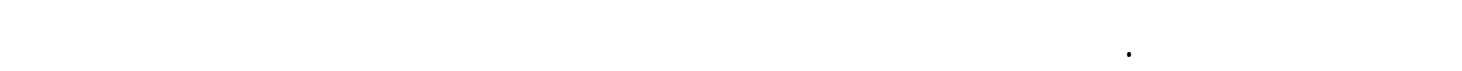
لسقراريتها العالية مقارنة مع العينة غير مطلية.

\begin{abstract}
:
Bioactive coating on composite implants facilitates biological fixation between the prosthesis and the hard tissue, and increases the long-term stability and integrity of the implants. It produces an intermediate region between bone and implant. Hydroxyapatite coating $\mathbf{C a}_{10}\left(\mathbf{P O}_{4}\right)_{6}(\mathbf{O H})_{2}$ was carried out on stainless steel 321 AISI substrate by chemical method, this coating can forms strong chemical bonds with bone in vivo because it has the same mineral component of bone.

The x-ray diffraction (XRD) technique were employed to investigate formed phases on the specimen surface. The coating formed is pure hydroxyapatite free from other phases like tri- or tetra calcium phosphate.
\end{abstract}


Electrochemical study involving cyclic polarization experiment was carried out to assess the corrosion resistance behaviour of Hydroxyapatite coated 321 SS comparing with uncoated specimen in Ringer's solution. The results of cyclic polarization have indicated the efficiency of coated specimen which showed high stability Compared with the uncoated specimen.

\section{Introduction:}

Hydroxyapatite (HAP) was first identified as being the mineral component of bone. However it was not until about 25 years ago that synthetic hydroxyapatite was accepted as a potential biomaterial for use in orthopedics, bone grafts and dentistry. It is one of a limited number of materials that forms strong chemical bonds with bone in vivo, while remaining stable under the harsh conditions encountered in the human body. These properties place hydroxyapatite into the class of biomaterials known as surface active or bioactive materials.

We can define the term "biomaterial" as a synthetic material that is in contact with the human tissue and that does not cause a toxic response within the body as a consequence of its presence. The use of nonbiological materials as surgical implants is not new and especially the substitution of bone parts in the human body have been reported for centuries (H. Ohgushi et al, 2000). Any biomaterials must have some key properties in order to be used in contact with human tissues, and, apart from the specifications for its particular application, it has to be noncarcinogenic, must have a good resistance to corrosion and to wear, and finally the products of corrosion must be less toxic as possible (D.F. Williams, 1996).

Bioactive hydroxyapatite has a substantial interest because of its chemical similarity to the calcium phosphate minerals in biological hard tissue, and its ability to form a strong chemical bond with bone (N. Ramesh Babu et al, 2004). Calcium phosphate coatings especially hydroxyapatite are used clinically on joint replacements and the main goal is to accelerate bone ingrowth to implant surface and thus fixation of the prosthesis.

At the material level, bone is composed of organic and inorganic components. The organic part is $90 \%$ type collagen and the inorganic part is mainly hydroxyapatite with a small percentage of other ions such as carbonate, magnesium and fluoride etc.. Synthetic hydroxyapatite has been used for bone replacement and augmentation due its excellent biocompatibility and osteoconductive potential (D. Siva Rama Krishna et al, 2002)

K. Prabakaran and S. Rajeswari, 2006 developed hydroxyapatite powder from fish bone through heat treatment method, and HAP developed from fishbone was electro- phoretically deposited on type $316 \mathrm{~L} \mathrm{SS}$ and showed that the corrosion resistance behaviour of fish bone originated-HAP coated $316 \mathrm{~L} \mathrm{SS}$ is nobler than the pristine $316 \mathrm{~L} \mathrm{SS}$. And 
suggests that fish bone as a useful inexpensive ceramic material to develop phase pure hydroxyapatite crystals, which can be applied as a coating on $316 \mathrm{~L}$ SS to prevent the release of metal ions and to improve the corrosion resistance of the metal.

R. Murugan et al, 2006 designed scaffolds for bone tissue restoration from naturally-derived biomaterials that mimic the composition and structure of natural bone, by a simple method for processing biological apatite (BAp) from bovine bone and using the Chemical and low temperature heat treatments for the processing of BAp scaffold. And showed that the Bap possesses porous morphology and the pores are in the range of micrometers to a anon meters in diameter.

Coating of hydroxyapatite have been done by a variety of techniques including dip coating into a powder suspension, electron beam evaporation combined with ion beam mixing, electrophoretic deposition, sol-gel, laser ablation, plasma spray, rf sputtering methods. These suffer from various drawbacks. In this project a unique chemical method for the deposition of hydroxyapatite coating on Stainless steel substrate is described.

The good mechanical properties of stainless steel alloys makes it one of the metal alloys used in orthopedic, but this metallic alloys are bioinert and do not bond chemically to bone as does hydroxyapatite HAp, Which makes the coating with hydroxyapatite necessary. In addition, The resistance of hydroxyapatite to corrosion in chloride environment is excellent and better than stainless steel alloys (K. Prabakaran and S. Rajeswari, 2006).

The project aims to coating stainless steel substrate with hydroxyapatite by chemical method and used clinically on joint replacements in orthopedics. And aims to studying the corrosion resistance of HAp coating in Ringer's solution and its compared with uncoated specimen.

\section{Materials and method:}

The deposition of hydroxyapatite coating is done by two stages, in the first stage, the stainless steel 321 AISI plate which is used as a substrate with dimensions $20 \times 10 \times 2 \mathrm{~mm}$ and the elemental composition is given in Table (1).

Table (1) Chemical composition of type 321AISI SS (Shahrour,1994)

\begin{tabular}{|c|c|}
\hline Element & Wt\% \\
\hline $\mathrm{Cr}$ & 18.636 \\
\hline $\mathrm{Ni}$ & 8.962 \\
\hline $\mathrm{Ti}$ & 0.21 \\
\hline $\mathrm{Mn}$ & 1.477 \\
\hline $\mathrm{C}$ & 0.0544 \\
\hline $\mathrm{S}$ & 0.0015 \\
\hline $\mathrm{Si}$ & 0.604 \\
\hline $\mathrm{Fe}$ & Balance \\
\hline
\end{tabular}


the metal specimens are made rough by mechanically polished using silicon carbide papers of $120-600$ grit and then heated in $\mathrm{KOH}(2 \mathrm{M})$ solution at 90 degree centigrade for two hours.

In the second stage, a chemical bath was prepared for Hydroxyapatite coating, where the idea of chemical bath deposition is based on a controlled performing of the following reaction:

$$
10 \mathrm{Ca}^{(+2)}+6 \mathrm{PO}_{4}^{(-3)}+2 \mathrm{OH}^{(-)}=\mathrm{Ca}_{10}\left(\mathrm{PO}_{4}\right)_{6}(\mathrm{OH})_{2}
$$

The stock solution for the chemical bath was prepared by dissolving $17.5 \mathrm{gm}$ of $\mathrm{KOH}$ in $75 \mathrm{ml}$ double distilled water. In the prepared solution $12.5 \mathrm{gm}$ of di-sodium salt of EDTA (Ethylene diammine tetra acetic acid) was added. When the salts dissolved, $3.75 \mathrm{gm}$ of potassium dihydrogen phosphate is added. Another solution of calcium nitrate is prepared by dissolving $6.8 \mathrm{gm}$ of the salt in $25 \mathrm{ml}$ of double distilled water. The first solution was kept on a magnetic hot plate with stirrer and the second solution is slowly added.

The chemical bath deposition was performed in a $50 \mathrm{ml}$ beaker by immersing the steel plate in the prepared solution. The beaker containing the solution along with the steel plate is now placed in a water bath and heated for two hours at 70 degree centigrade. Then the temperature was raised to 95 degree centigrade and the solution was maintained at the above temperature for 3 hours. After deposition the substrate was taken out, washed with water and dried. The coating layer produced it has good adherence with the substrate alloy.

\section{Electrochemical measurements :}

All HAP coated stainless steel specimens were subjected to cyclic polarization experiment in Ringer's solution. The chemical composition (mmol/l) of the Ringer's solution (as the same in the human body) was $\mathrm{Na}+147.1, \mathrm{~K}^{+} 4.02, \mathrm{Ca}^{++} 2.25, \mathrm{Cl}^{-} 155.55$. The $\mathrm{pH}$ was adjusted to 7.4 and temperature was maintained at $37^{\circ} \mathrm{C}$. The electrochemical cell of 500 $\mathrm{ml}$ capacity fitted with saturated calomel electrode (SCE) as reference electrode, platinum foil as auxiliary electrode and stainless steel as working electrode was used for all measurements.. The scan rate of 2 $\mathrm{mV} / \mathrm{s}$, in potentiostat (model PGSTAT 12 with FRA, Autolab, The Netherlands B.V) was used for conducting the polarization experiments.

\section{Results and Discussion:}

After coating the specimen, crystal structure of the coatings was investigated with an X-ray diffractometer which was done using automated PHILIPS PW 1140/90 diffractometer at a scan rate of $2^{0} 2 \theta$ $/$ min over a $2 \theta$ range of $5^{\circ}-50^{\circ}$. All sample XRD patterns revealed a basic apatite structure as in figure (1) and table (2), proving that phase purity of Hydroxyapatite Hap (The presence of some high peaks in the XRD results may be due to substrate alloy). 


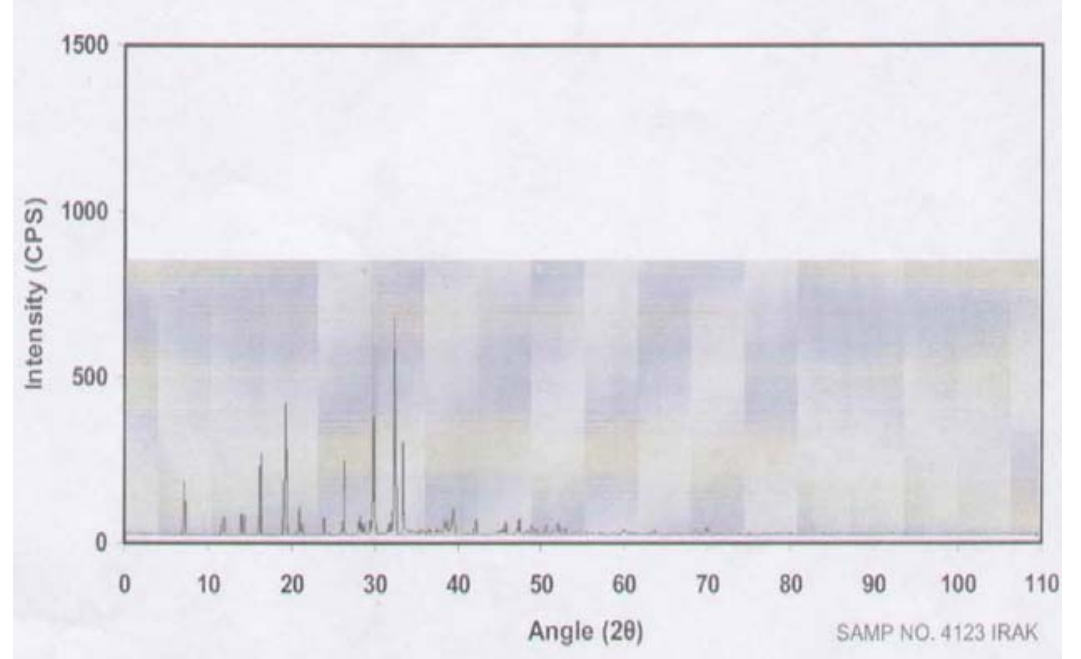

Figure (1) X-ray diffraction pattern for the SS 321 with HAp coated

Table (2): the value of (d) spacing and intensity of X-ray diffraction for coated specimen

\begin{tabular}{|c|c|c|}
\hline Value of two theta $(\operatorname{deg})$ & $\mathrm{d}=\mathrm{n} \lambda / 2 \sin \theta\left(\mathrm{A}^{\mathrm{o}}\right)$ & Value of intensity (I/Io) \\
\hline 32 & $2.79^{*}$ & 100 \\
\hline 29.5 & $3.02^{*}$ & 55 \\
\hline 33.5 & $2.67^{*}$ & 45 \\
\hline 26 & $3.42^{*}$ & 40 \\
\hline
\end{tabular}

${ }^{*} \mathrm{Ca}_{5}\left(\mathrm{PO}_{4}\right)_{3}(\mathrm{OH})$

\section{Cyclic polarization studies:}

The corrosion potential, variation with time of immersion of stainless steel 321 AISI alloy in Ringer's solution for a period, the Fig.( 2 ) shows the corrosion resistance behavior of HAP coated stainless steel 321 AISI comparing with uncoated specimen in Ringer's solution. The results of cyclic polarization have indicated the efficiency of coated specimen which showed high stability Compared with the uncoated specimen as shown from fig (2). The current density values show that stable passive film is formed on the surface coated stainless steel 321 AISI and also due to the prolonged interaction of calcium ions present in the Ringer's solution.

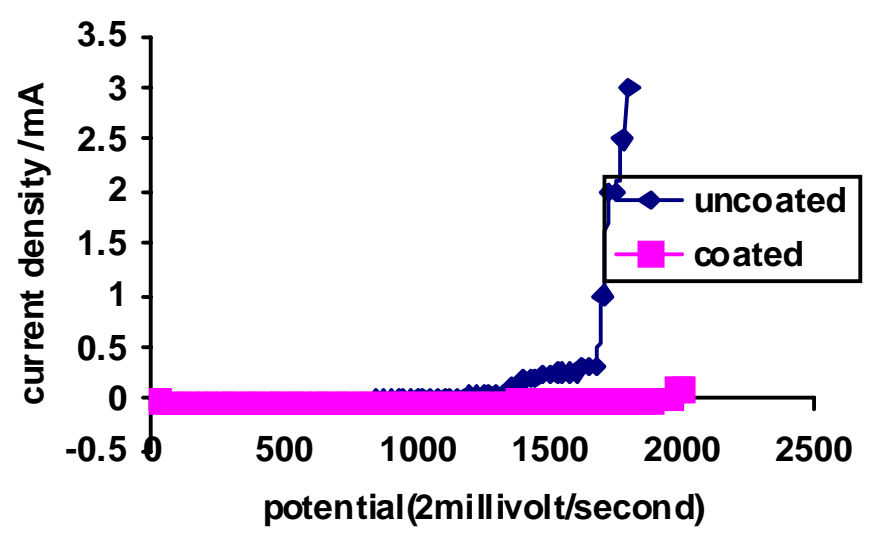

Figure ( 2 ) : the corrosion resistance behavior of HAP coated stainless steel 321 AISI comparing with uncoated specimen in Ringer's solution 


\section{Conclusion:}

The above-proposed work leads to a simple method to develop phase pure Hydroxyapatite HAP. The method can be used to coat any odd shaped object. The coating formed is of pure hydroxyapatite free from other phases like tri-or tetra calcium phosphate as shown in fig (1) and table (2). And the deposition temperature is below 100 degree centigrade with potential for deposition onto polymer substrates. HAp coatings are able to enhance bone in growth to implant surface and thus fixation of the prosthesis. The dense fracture free coating can improve adhesion with the substrate and also act as a barrier layer between implant surface and body fluids preventing dissolution of the metal. In addition, The resistance of hydroxyapatite to corrosion in Ringer's solution is excellent and better than pristine stainless steel alloys as shown in fig (2).

\section{References:}

1) D. Siva Rama Krishna, C.K. Chaitanya, S.K. Seshadri and T.S. Sampath Kumar, (2002), Fluorinated hydroxyapatite by hydrolysis under microwave irradiation, Trends Biomater. Artif. Organs. Vol. 16 (1) pp 15-17.

2) D.F. WILLIAMS, (1996), The Williams dictionary of Biomaterials, Liverpool University press.

3) H. OHGUSHI, M. ISHIMURA, T. HABATA, S. TAMAI, (2000), Porous ceramics for intra-articular depression fracture, Biomaterials and bioengineering handbook, New York, Marcel Dekker, 2000, pg. 397-405.

4) K. Prabakaran and S. Rajeswari, (2006), Development of Hydroxyapatite from Natural Fish Bone Through Heat Treatment, Trends Biomater. Artif. Organs, Vol. 20(1), pp 20-23.

5) N. Ramesh Babu, Sushant Manwatkar, K. Prasada Rao and T. S. Sampath Kumar, (2004), BIOACTIVE COATINGS ON 316L STAINLESS STEEL IMPLANTS, Trends Biomater. Artif. Organs. Vol. 17(2) pp 43-47.

6) R. Murugan1, T. S. Sampath Kumar and S. Ramakrishna, (2006), Scaffolds for Bone Tissue Restoration from Biological Apatite, Trends Biomater. Artif. Organs, Vol. 20(1), pp 35-39.

7) Shahrour, Khalide Mijeed Nasser, (1994), Some aspects of chromium and silicon-aluminide coatings on 321 stainless steel alloy, thesis submitted to university of mosul college of science. 